\title{
PELATIHAN PEMANFAATAN MARKETPLACE PADA UMKM DALAM MASA COVID-19
}

\author{
Fina Fitriyana, Anum Nuryani, Tati Rosyati, dan Yolanda Gusvia \\ Universitas Pamulang \\ dosen02518@unpam.ac.id
}

\begin{abstract}
This community service is in collaboration with the South Tangerang "Rumah Pemberdayaan Masyarakat" (RPM). The purpose of this community service is to introduce the marketplace and to apply it to SMEs. These 100 UKM were participating in this activity. The socialization process was carried out simultaneously and together at Pamulang University. This community service activity enters into groups with at least one servant for one participant on 31 October - 5 November 2020. The methods in this activity are counseling, tutorials, discussions, mentoring, and assessment. Each group consists of four facilitators and one participant. Through this activity, SMEs can take advantage of and understand the use of one of the marketplaces / social media. This activity has expected to give benefit to all parties, including SMEs, government, and academics.
\end{abstract}

Keywords: Small Business Enterprise, Marketplace, RPM

\begin{abstract}
ABSTRAK
Pengabdian kepada masyarakat ini bekerja sama dengan Rumah Pemberdayaan Masyarakat (RPM) Tangerang Selatan. Tujuan dari pengabdian masyarakat ini adalah untuk mengenalkan penggunaan marketplace dan mengaplikasikannya pada UKM. Ada 100 UKM yang mengikuti kegiatan ini. Proses sosialisasi dilakukan secara serentak dan bersama di Universitas Pamulang. Kegiatan pengabdian masyarakat ini terbagi dalam beberapa kelompok dengan minimal satu pengabdi untuk satu peserta pada 31 Oktober - 5 November 2020. Metode dalam kegiatan ini adalah penyuluhan, tutorial, diskusi, pendampingan dan asesmen. Setiap kelompok terdiri dari empat fasilitator dan satu peserta. Melalui kegiatan ini, UKM dapat memanfaatkan dan memahami penggunaan salah satu marketplace / media sosial. Pengabdian kepada masyarakat ini diharapkan dapat bermanfaat bagi berbagai pihak baik UKM, pemerintah maupun akademisi.
\end{abstract}

Kata Kunci: UKM, Marketplace, RPM 


\section{A. PENDAHULUAN}

Marketplace merupakan media online yang dapat dijadikan wadah untuk bertemunya antara penjual dan pembeli sehingga dapat terciptanya transaksi jual-beli. Tidak hanya memberikan kemudahan dalam bertransaksi, namun Marketplace juga dapat memperluas jangkauan pangsa pasar bagi pelaku bisnis UMKM. Sehingga dapat lebih mudah dalam memasarkan produknya dengan lebih efektif dan efisien.

Umumnya produk yang dihasilkan dan ditawarkan para pelaku UMKM tidak dapat dianggap remeh, produk UMKM memiliki ciri khas yang berbeda antar satu jenis produk yang sama pun sangat sering terjadi. Untuk itu kelihaian dalam memasarkan produk harus ditingkatkan, akibat tingginya persaingan. Tidak hanya soal pemasaran kesiapan pengelolaan 'rumah tangga' industri juga harus dipersiapkan sebaik mungkin, diantaranya kesiapan dalam menerima perkembangan tekhnologi di bidang pemasaran. Saat ini semakin marak dan berkembangnya aplikasi penjualan online atau biasa disebut dengan Marketplace. namun pengelolaan bisnis, pengelolaan keuangan usaha, pengelolaan stok barang sampai pada pengelolaan pelayanan konsumen. Untuk mempersiapkan 'rumah tangga' industri demi tetap bertahannya suatu usaha, para pelaku UKM perlu dibantu serta didampingi.

Di Indonesia khususnya Jabodetabek, para pelaku UMKM banyak dibantu oleh Rumah Pemberdayaan Masyarakat (RPM). Rumah Pemberdayaan Masyarakat adalah sebuah lembaga nirlaba yang berfokus pada pelatihan dan pendampingan dalam berbagai programprogram pemberdayaannya. Selain itu, dalam setiap program Rumah Pemberdayaan Masyarakat menekankan kepada penguasaan bidang Digital. Kenapa harus Digital? karena saat ini dunia menuju kehidupan yang serba otomatis, manusia mulai tergantikan oleh mesin, software dan peralatan lainnya yang dapat bekerja 24 jam tanpa istirahat sebagaimana manusia yang ada batasnya dalam bekerja. Dengan alasan itu maka penguasaan akan digital marketing sangat ditekankan untuk memenangi persaingan di dunia nyata baik tingkat lokal maupun internasional.

Perkembangan pengguna internet, online shopper dan penjual yang menggunakan ecommerce semakin tahun semakin meningkat. Maka hal tersebut menjadi peluang untuk UMKM sehingga perlu adanya penghubung antara pelaku UMKM dan perkembangan internet untuk memaksimalkan bisnis UMKM. Komunitas UMKM yang dikembangkan pada penelitian ini yaitu komunitas UMKM yang bergerak di bidang sosial khususnya social entrepreneurship, karena komunitas social entrepreneurship dapat dijadikan sebuah solusi untuk masalah sosial yang ada di masyarakat. Harapannya komunitas social entrepreneurship dapat menjadi penghubung antara penjual dan pembeli.

UMKM yang menjadi produsen dari produk lokal dan pemasaran digital yang digunakan untuk mempermudah pemasaran produk menggunakan perkembangan internet terhadap bisnis ecommerce. Indonesia merupakan negara yang memiliki movement yang tinggi terhadap pergerakan komunitas social entrepreneurship, contoh komunitas yang tercatat yaitu Rumah Pemberdayaan Masyarakat (RPM).

Dengan perkembangan teknologi internet saat ini, dapat dijadikan solusi untuk mempermudah perkembangan dan perluasan pasar UMKM dengan bantuan yang diberikan oleh komunitas UMKM yang berfokus pada bidang sosial. Sehingga dibutuhkan suatu wadah yang dapat menampung produk-produk UMKM yang ada di seluruh Indonesia untuk meningkatkan distribusi produk dalam negeri. Salah satu model bisnis yang dapat di gunakan yaitu bisnis e-commerce yang memeberikan peluang baru bagi UMKM dalam mengembangkan usaha dan bentuk e-commerce yang dikembangkan saat ini yaitu Marketplace. 
Dikutip dari situs sirclo pertumbuhan e-commerce di Indonesia memang bisa dikatakan sangat pesat, bahkan menjadi salah satu negara dengan pertumbuhan e-commerce terpesat. Menurut ICD, pertumbuhan e-commerce Indonesia merupakan yang terbesar di kawasan Asia Tenggara. Dari banyaknya transaksi online tersebut, 60 persennya dilakukan melalui platform Marketplace seperti Tokopedia, Shopee, Lazada, dan Marketplace lainnya. Kategori produk yang paling banyak dibeli yakni sekitar $70 \%$ dari total transaksi online antara lain produk elektronik, fashion, kesehatan dan kecantikan. Menurut laporan Ernst \& Young, bisnis online di Indonesia yang saat ini didominasi oleh UMKM berkembang sebesar 40\% setiap tahunnya. E-commerce dan Marketplace memiliki potensi pasar yang begitu besar dan luas. Bagaimana awalnya perkembangan Marketplace hingga bisa seperti sekarang ini?

Lebih lanjut lagi, data tersebut menunjukkan sekitar 30 juta masyarakat Indonesia pernah melakukan transaksi online, menciptakan pasar dengan nilai setidaknya sebesar USD 8 miliar. Pasar ini diprediksi dapat terus berkembang hingga USD 40 miliar dalam 5 tahun ke depan. Tren Marketplace terus berkembang seiring perkembangan internet dan teknologi digital di Indonesia. Pada tahun 2009, Tokopedia berdiri dan mengalami perkembangan yang sangat pesat. Marketplace pun menjadi semakin populer sebagai tempat bagi masyarakat untuk berbelanja berbagai kebutuhan. Pada tahun 2010, Marketplace Bukalapak turut berdiri.

Saat ini, jumlah Marketplace sudah begitu banyak dengan kekuatan industrinya masing-masing. Begitu pula dengan pilihan metode pembayaran yang juga semakin beragam. Proses transaksi yang tadinya terbatas yakni dengan debit dan kredit kini bisa dilakukan melalui smartphone. Bahkan sejumlah Marketplace menyediakan dompet elektroniknya sendiri. Hal ini membuat semakin banyak konsumen yang lebih memilih untuk berbelanja di Marketplace karena kemudahan yang ditawarkannya. Pertumbuhan ini dikatakan dapat membuat e-commerce menjadi penggerak utama ekonomi digital. Diprediksi, pasar ecommerce akan mampu menyumbang USD 100 miliar di tahun 2025.

Solusi dari permasalahan yang sedang dihadapi UMKM saat ini yaitu rancangan Marketplace yang dapat digunakan oleh komunitas UMKM. Marketplace tersebut memiliki fungsi utama yaitu suatu web yang didalamnya terdapat forum yang dapat digunakan untuk komunitas saling berbagi informasi. Selain itu, Marketplace merupakan model yang dapat memudahkan UMKM untuk memasarkan produk yang dihasilkan dan suatu model yang memberikan informasi bisnis UMKM. Solusi yang ditawarkan penulis akan melakukan penelitian untuk merancang Marketplace yang sesuai dan dibutuhkan oleh komunitas UMKM untuk mengembangkan bisnis UMKM melalui pemasaran produk UMKM.

\section{B. METODE PELAKSANAAN KEGIATAN}

\section{Peserta PKM}

Peserta PKM yang dipilih adalah para pelaku UMKM yang tergabung menjadi anggota Rumah Pemberdayaan Masyarakat Institute sebanyak 100 orang. Penetapan sasaran ini merupakan suatu upaya untuk meningkatkan kinerja keuangan UMKM yang sudah terdaftar di Rumah Pemberdayaan Masyarakat Institute sehingga perkembangannya dapat diketahui dan dipantau dengan mudah. Lebih jauh dari itu, harapannya peserta pelatihan dapat menularkan ilmu yang didapatkan kepada pelaku UMKM lain yang berada di sekitarnya.

\section{Tempat dan Waktu}

Kegiatan penyuluhan, pendampingan dan konsultasi dilakukan di kampus Universitas Pamulang, Jl. Surya Kencana No. 1, Pamulang, Kota Tangerang Selatan. Waktu penyuluhan dilakukan di tanggal 31 Oktober pukul 09:00 sampai dengan selesai dan mulai 1-6 November 
2020 hari minggu-kamis. Pendampingan dan konsultasi dilakukan pada hari minggu-jumat pukul 15:00 dan 20:00 - 23:00 atau di jam yang telah disepakati.

\section{Metode Kegiatan}

Pelaksanaan kegiatan Pengabdian Pada Masyarakat ini dilakukan dengan menggunakan metode ceramah, tutorial, diskusi, pendampingan dan konsultasi, dan assesment. Adapun sistematika pelaksanaan kegiatan pengabdian ini adalah sebagai berikut:

1. Langkah 1 (Metode Ceramah): Peserta diberikan motivasi agar memiliki kemauan untuk menggunakan akuntansi dalam kegiatan bisnisnya. Selain itu, peserta diberikan materi gambaran umum tentang pemasaran UMKM dalam dunia Marketplace

2. Langkah 2 (Metode Tutorial): Peserta pelatihan diberikan materi mengenai Marketplace yang ada di Indonesia mulai dari pengenalan Marketplace sampai dengan penggunaan Marketplace untuk memasarkan produk.

3. Langkah 3 (Metode Diskusi): Peserta pelatihan diberikan kesempatan untuk mendiskusikan permasalahan yang berkaitan dengan pemasaran produk UMKM yang selama ini dihadapi. Langkah ketiga diselenggarakan selama 1 jam.

4. Langkah 4 (pendampingan dan konsultasi): peserta diberi kesempatan untuk didampingi selama 1 bulan dalam menjual produknya pada marketplace. Peserta diberi kesempatan untuk bertemu dengan para mentor di waktu dan tempat yang telah disepakati.

5. Langkah 5 (Evaluasi/ Assesment) : tahap pertama evaluasi, peserta dtinjau tingkat penjualannya melalui marketplace dan mengevaluasi hasil review yang diberikan oleh customer. Sehingga diharapkan tidak memberikan kesan buruk terhadap penilaian toko tersebut di marketplace.

\section{HASIL DAN PEMBAHASAN}

Ravi_Cake merupakan Brand dari UMKM yang dimiliki oleh Bu Retno. Akibat pandemi ini Bu Retno, melakukan pemsarannya melalui Sosial Media@ @avi-Cake (Instagram) dan Tokopedia (Ravi_cake) namun sempat off karena kurang maksimalnya pemanfaatan Marketplace.

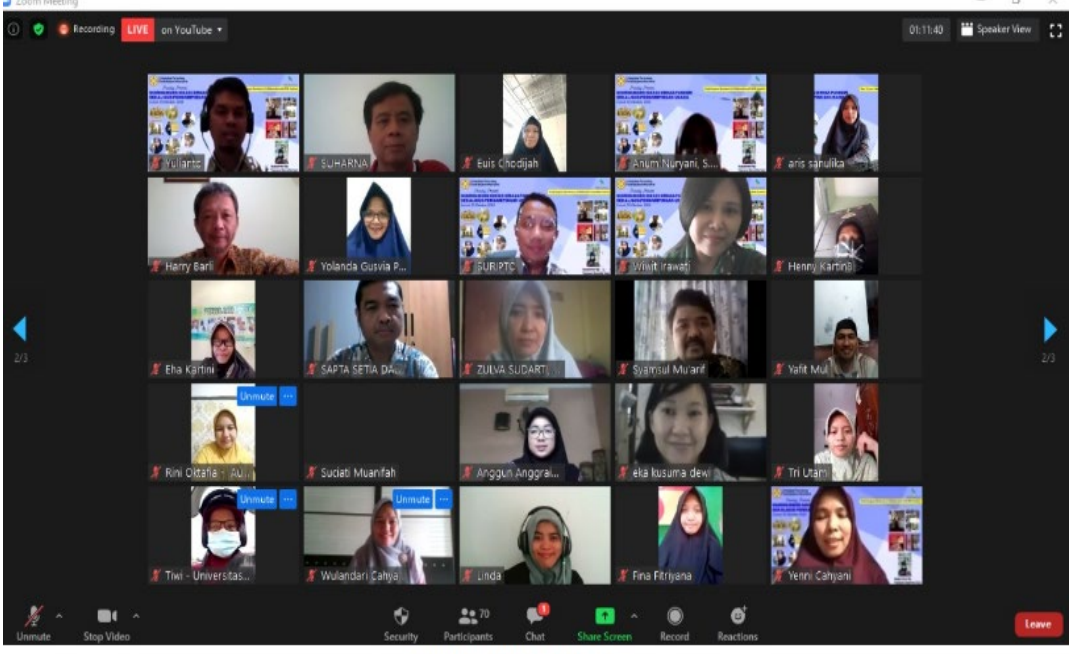

Gambar 1. Sosialisasi
Gambar

merupakan pertama dilakukan pada tanggal 31 November 2020 melalui zoom meeting pukul 09:00. Dikarenakan adanya pandemi maka kegiatan PKM ini dilakukan secara Daring. Acara pertama diawali dengan sambutan oleh Ibu Effryanti, SE., Ak., MSi., CA selaku Ketua Program Studi Akuntansi S1

Universitas Pamulang, sambutan Ketua RPM dan pembagian kelompok UKM oleh Ibu Ratih Qadarti Anjilni, SE., M.Ak. yang akan dibina oleh anggota pengabdi.

Kegiatan selanjutnya merupakan Pelaksanaan pelatihan Pada hari Minggu 1 November 2020 sampai dengan Kamis 5 November 2020 melalui Aplikasi WhatsApp. Selama kegiatan peserta dierikan informasi mengenai marketplace yang ada di Indonesia terutama top 5 dari 
marketplace yakni Tokopedia, Shopee, Bukalapak, Lazada dan BliBli berdasarkan jumlah pengunjungnya yang dikutip situs ajaib yang berjudul Daftar Marketplace Indonesia 2020 dengan Kunjungan Terbanyak.

Dalam penyampaian materi disampaikan jenis-jenis dan fitur yang tersedia serta perbedaan tiap marketplace berdasarkan pangsa pasar, promo dan tampilan. Selama pendampingan banyak diskusi yang dilakukan mulai dari bagaimana cara promosi dan pemanfaatan media sosial sehingga pemasaran bisa lebih maksimal.

Penggunaan media sosial merupakan penunjang marketplace atau marketing. Proses branding perlu dilakukan dengan memanfaatkan media sosial seperti instagram menjadi pilihan yang bisa membuat brand UKM menjadi terkenal. Sudah tak asing lagi bahwa promosi produk terutama makanan dilakukan oleh reviewer baik melalui channel Youtube oleh youtuber maupun melalui instagram oleh selebgram.

Beberapa penjualan makanan mengalami peningkatan setelah melakukan promosi melalui selebgram. Maka dari itu proses promosi Ravi_Cake, kami coba bantu informasikan terkait selebgram yang dapat membantu proses promosinya.

Selain promosi yang perlu diperhatikan untuk memanfaatkan marketplace yakni tampilan produk yaang menarik dan proses layanan terhadap pelanggan. Meninjau kembali media promosi yang dilakukan UKM sudah ada peningkatan, tidak hanya foto namun video dan testimoni juga ditampilkan.

\section{KESIMPULAN DAN SARAN}

\section{Simpulan}

Kegiatan pelatihan akuntansi UMKM bagi usaha mikro, kecil, menengah (UMKM) untuk meningktakan penjualan dan memperluas pasar untuk produk UMKM berjalan dengan lancar. Sekaligus memperkenalkan perkembangan digital marketing kepada pelaku UMKM. Semua peserta antusias mengikuti acara hingga selesai dan merasakan manfaat pelatihan bagi kemajuan usaha mereka.

Saran

Saran disusun berdasarkan analisis keunggulan dan kelemahan atau hal yang sudah dan belum tercapai dari kegiatan serta keberlanjutan kegiatan Serupa dapat dilaksanakan kembali dengan peserta (audience) yang lebih banyak/luas, dan dengan topik lainnya. Di samping itu penggunaan virtual premium kampus bisa menjadi media pendukung agar bisa lebih memaksimalkan penyampaian materi. Program pengabdian lanjutan perlu dilakukan agar tetap terbantunya masyarakat khususnya para pelaku UMKM.

\section{Ucapan Terimakasih}

Seenap rasa syukur kami atas terlaksananya kegiatan Pengabdian ini, kami sampaikan kepada seluruh pihak yang telah membantu demi kelancaran dan keberhasilan acara pengabdian dengan judul "Pelatihan Pemanfaatan Marketplace pada UMKM dalam Masa Covid-19", yakni:

1. Bapak Dr. H Dayat Hidayat M.M., selaku Rektor Universitas Pamulang.

2. Bapak Dr. Ali Maddinsyah, S.E., M.M., selaku Ketua LPPM Universitas Pamulang

3. Bapak H. Endang Ruhiyat, S.E., M.M., CSRA., CMA selaku Dekan Fakultas Ekonomi

4. Ibu Effriyanti, SE., Ak., MSi., CA selaku Ketua Program Studi Akuntansi

5. Ibu Ratih Qadarti Anjilni, S.E., M.Ak, selaku dosen yang telah berjasa mengenalkan RPM dengan UNPAM

6. Bapak Husen selaku ketua Rumah Pemberdayaan Masyarakat Institute

7. Ibu Retno selaku peserta UMKM dengan brand Ravi_Cake 


\section{E. DAFTAR PUSTAKA}

Abraham Wasli, Sejarah Awal Berdirinya Marketplace Tokopedia, Shopee, Bukalapak, Lazada, Blibli Dan Jdid, Teknologi.Id, (September 2020), Https://Teknologi.Id/Os/Sejarah-Awal-Berdirinya-Marketplace-Tokopedia-ShopeeBukalapak-Lazada-Blibli-Dan-Jdid

Artaya, I. Putu; Purworusmiardi, Tubagus. Efektifitas Marketplace Dalam Meningkatkan Konsentrasi Pemasaran Dan Penjualan Produk Bagi Umkm Di Jawa Timur. Ekonomi Dan Bisnis, Universitas Narotama Surabaya, 2019, 1-10.

Feriawan Hidayat, Kehadiran Marketplace Berikan Manfaat Besar Bagi Umkm, Berita Satu (12 November 2019), Https://Www.Beritasatu.Com/Digital/584810/KehadiranMarketplace-Berikan-Manfaat-Besar-Bagi-Umkm\#!

Ilham Mubarok, Apa Itu Marketplace? Pengertian, Jenis, Dan Contohnya, Niagahisterblog, (2019) Https://Www.Niagahoster.Co.Id/Blog/Marketplace-Adalah/

Pahlevi, Pengertian Marketplace Dan Jenis-Jenis Marketplace, Pahlevi, (2017) Https://Www.Pahlevi.Net/Pengertian-Marketplace/

Puspita Karyati, Ika, E-Commerce Untuk Umkm Dan Pertumbuhan Ekonomi Indonesia, Kementerian Keuangan Badan Pendidikan Dan Pelatihan Keuangan, (13 September 2019), Https://Bppk.Kemenkeu.Go.Id/Content/Berita/Pusdiklat-Keuangan-UmumEcommerce-Untuk-Umkm-Dan-Pertumbuhan-Ekonomi-Indonesia-2019-11-05Ebe6e220/

Setiawan, Budi. Edukasi E-Commerce Pada Pelaku Usaha Mikro, Kecil Dan Menengah (Umkm) Di Kota Palembang. Jurnal Abdimas Mandiri, 2018, 2.2.

Suryanto, Tommi. Penerapan E-Marketplace Pada Distro Silver Squad. Konferensi Nasional Sistem Informasi (Knsi) 2018, 2018. 